\title{
Microstructural Mechanisms and Advanced Characterization of Long and Small Fatigue Crack Growth in Cast A356-T6 Aluminum Alloys
}

\author{
Anthony G. Spangenberger ${ }^{*}$, Diana A. Lados ${ }^{1}$, Mark Coleman², Soran Birosca ${ }^{2}$, and Mark Hardy ${ }^{3}$ \\ ${ }^{1}$ Worcester Polytechnic Institute, Integrative Materials Design Center, Worcester, MA 01609, USA \\ ${ }^{2}$ Institute of Structural Materials, College of Engineering, Swansea University, Swansea, SA1 8EN, UK \\ ${ }^{3}$ Rolls-Royce plc, Derby, DE24 8BJ, UK
}

\begin{abstract}
Fatigue crack growth-based design is a significant modern engineering consideration for the transportation sector, and its implementation requires accurate characterization and understanding of crack propagation mechanisms with respect to microstructure. To support this goal, long and small fatigue crack growth studies were conducted on widely used A356-T6 cast aluminum alloys in various microstructural conditions. Microstructural variations were created through processing and chemistry means in order to systematically investigate the individual and combined effects of the materials' characteristic microstructural features on fatigue crack growth at all growth stages. Crack growth mechanisms and failure mode transitions are identified with respect to the eutectic Si morphology/distribution and grain structure by fractographic techniques and electron backscatter diffraction. Crack-microstructure interactions were investigated in depth across all crack sizes, and the respective roles of microstructural features were identified experimentally and further corroborated by numerical models. It is concluded that the eutectic Si phase enhances the alloys' fatigue crack growth resistance in early growth stages (by transferring stresses off of the $\alpha$-Al matrix), and progressively decreases due to damage localization. In later growth stages, the eutectic Si phase becomes increasingly detrimental to fatigue crack growth resistance because of its inherently low debonding strength and brittle fracture, as evidenced by the crack selectively following eutectic Si colonies.
\end{abstract}

Keywords: Small and long fatigue crack growth, Microstructural mechanisms, Electron backscatter diffraction, Stress concentrations, Aluminum alloys

\section{INTRODUCTION}

Light structural metals have been extensively applied throughout the transportation sector in recent years in order to reduce vehicle weight and enhance modern energy efficiency. Their use, however, is restricted by the engineering challenge of fatigue crack growth (FCG) and the need to mechanistically understand the fundamental physical phenomena governing the material's fatigue resistance and crack growth path. Specifically, the effect of the microstructure and processing conditions on FCG behavior at all growth stages must be thoroughly understood in order to integrate efficient damage-tolerant design methodologies for fatigue-critical structural components.

Fatigue cracks are often classified according to their size and characteristic propagation mechanisms as microstructurally-small (comparable to the scale of the microstructure and crack tip plasticity, requiring elastic-plastic fracture mechanics), physically-small (sampling a continuous representation of the microstructure; linear elastic fracture mechanics is applicable), and long cracks (subject to closure phenomena) [1]. Closure is the interaction of crack faces behind the crack tip, which shield the crack and lower the effective applied driving force. The magnitude of closure can be measured experimentally by various methods [2-7], including the adjusted compliance ratio (ACR) technique used in this work [8], in order to predict the physically-small crack growth behavior. Lados et al. [9] found that long crack growth threshold values in cast aluminum alloys are primarily affected by residual stress, roughness/microstructure, and corrosion-induced closure mechanisms. Further, in the absence of residual stresses and in comparing materials with similar oxidizing susceptibility, differences in closure behavior are predominantly roughness-induced. Wrought aluminum alloys are observed to exhibit a significant degree of closure (50-80\% of $\mathrm{K}_{\max }$ ) due to the planarity of slip and anisotropic properties, which promote tortuous crack paths and roughnessinduced closure [10]. For aluminum alloys in general, it is found that roughness-induced closure is the dominant

*Corresponding author e-mail:

aspangenberger@wpi.edu

(C) 2016. This manuscript version is made available under the Elsevier user license

http://www.elsevier.com/open-access/userlicense/1.0/ 
closure mechanism, owing to slip reversibility and non-homogeneous planar slip behavior [11], especially relevant to cast alloys due to their significant secondary phase content.

\begin{tabular}{|l|l|}
\hline \multicolumn{2}{|c|}{ NOMENCLATURE } \\
\hline $\mathrm{a}$ & Particle radius \\
\hline$\alpha$ & Grain boundary twist angle \\
\hline$\beta$ & Grain boundary tilt angle \\
\hline$\left[\mathrm{D}_{\mathrm{i}}\right]$ & Slip direction unit vector for all slip systems (for FCC, $\mathrm{i}=1-12)$ \\
\hline$[\mathrm{E}]$ & Grain boundary plane normal unit vector \\
\hline$\theta$ & Angle measured from particle center relative to load axis \\
\hline$[\mathrm{L}]$ & Nominal load axis unit vector \\
\hline $\mathrm{m}$ & Schmid factor \\
\hline$\mu$ & Shear modulus \\
\hline$\left[\mathrm{N}_{1}\right],\left[\mathrm{N}_{2}\right]$ & Slip system normal unit vectors for favored systems on either side of grain boundary \\
\hline$\left[\mathrm{N}_{\mathrm{i}}\right]$ & Slip system normal unit vector for all slip systems (for FCC, $\mathrm{i}=1-12$ ) \\
\hline$v$ & Poisson's ratio \\
\hline $\mathrm{r}$ & Radial distance from center of particle \\
\hline $\mathrm{R}_{\mathrm{t}}$ & Peak-to-valley roughness \\
\hline$\sigma$ & Far-field, nominal applied normal stress \\
\hline$\tau$ & Shear stress \\
\hline
\end{tabular}

Microstructural constituents further influence crack growth mechanisms at all growth stages and crack sizes. Physically-small and long crack growth mechanisms are influenced by the material's characteristic microstructure, as it effects the ability of the crack to deflect and dissipate stresses at the crack tip. Wang et al., reviewed the effects of eutectic structure, secondary dendrite arm spacing (SDAS), and matrix strength in Al-7\% Si-Mg cast alloys [12]. It was found that, in the absence of casting defects, fatigue life is enhanced for microstructures with spherodized (Srmodified) eutectic morphology, finer SDAS, lower Mg and Fe content, and greater yield strength. For hypoeutectic and eutectic $\mathrm{Al}-\mathrm{Si}-\mathrm{Mg}$ alloys, it was found that the plastic zone size controls growth mechanisms and transitions between mechanisms in long cracks [13]. Larger plastic zones are able to envelop more secondary phase particles (increasing the statistical likelihood of finding weak-link particles/interfaces), and correspond to more tortuous fracture surfaces and growth through/along the secondary phase. Microstructurally small cracks (MSCs) are sufficiently small to interact with discrete features of the microstructure and characteristically accelerate/decelerate as they approach/interact with barriers. These microstructural barriers have been correlated with fracture surface observations of grain boundaries in A535-F [14], Al-1\%Si-0.45\% Mg [1], and Al-7\% Si-0.3\% Mg [15] and eutectic Si particles in $\mathrm{Al}-7 \% / 13 \% \mathrm{Si}-0.45 \% \mathrm{Mg}[1]$.

The specific mechanisms of crack-microstructure interactions have further been the focus of extensive experimental and modelling research. Zhai et al. $[16,17]$ proposed a crystallographic mechanism for crack propagation across grain boundaries to describe acceleration/deceleration of MSCs. They indicated that the twist/tilt angles at the grain boundary between two neighboring grains control the resistance to MSC growth, and that the crack will propagate onto the slip plane that minimizes the twist angle (and thereby minimize the energy required to form new crack surfaces). The crystallographic mechanism is corroborated by experimental evidence in FCC systems by several researchers [18-20]. Schaef et al. [18] systematically varied the crack length, grain-grain orientation, and grain boundary inclination during MSC growth in a Ni superalloy in order to isolate their individual effects on crack-grain boundary interactions, and observed agreement with the Zhai model. In some cases, a nano-scale zig-zag growth behavior was observed with the crack alternating between competing (111) planes in order to minimize overall energy 
expenditure. Furthermore, they show that the crack will not necessarily transmit across the boundary to the slip system with the highest resolved shear stress (Schmid factor) when this system has a high twist/tilt angle. Prasad Reddy et al. [19] used a 3D dislocation dynamics investigation to show that low twist and tilt orientations create a strong localization of plastic deformation and facilitate crack transmission, whereas large misorientations broaden the plastic strain distribution and improve grain boundary resistance to MSC growth. In an X-ray microtomography study of a cast Al-7\% Si- $0.3 \% \mathrm{Mg}$ alloy (average grain size of $300 \mu \mathrm{m}$ ) by Ludwig et al. [20], it was shown that large twist angles can result in a transition from transgranular to intergranular crack growth, whereas tilting was accommodated by crack transmission and transgranular growth only. With the advent of high intensity synchrotron light sources, several researchers [21-23] have investigated the 3D crack path and crack-microstructure interactions with both in-situ and ex-situ (after test) techniques. These techniques, while enabling access to damage mechanisms in 3D (in contrast with trace measurements and fractographic analysis on the surface) are limited by spatial resolution (on the order of $1 \mu \mathrm{m}$ with current techniques) and reconstruction artifacts, prohibiting the investigation of smaller features, which often significantly influence FCG.

In contrast with the large number of studies investigating the mechanisms of crack-grain boundary interactions, relatively fewer studies have been conducted to assess the role of secondary phases. Chen et al. [24] investigated MSC growth mechanisms in a 2524-T3 Al alloy $(210 \mu \mathrm{m} \times 170 \mu \mathrm{m} \times 25 \mu \mathrm{m}$ grain size; $\sim 4 \mu \mathrm{m}$ uniformly distributed $\mathrm{Al}_{2} \mathrm{Cu}$ phase), and found that grains are largely responsible for the acceleration/deceleration mechanisms, whereas the inclusions debonded and increased the growth rate by crack bridging. To the authors' best knowledge, no consistent and integrated studies have been conducted in the A356 alloy system regarding the individual effects of crystallographic and secondary phase control of crack growth mechanisms across all size scales. To address this need, mechanisms of long and small crack growth are characterized across all size scales and in various microstructural conditions by combined fractographic and electron backscatter diffraction (EBSD) techniques in order to elucidate the microstructural effects, and support materials/process optimization for structural applications.

\section{MATERIALS, TESTING, CHARACTERIZATION, AND ANALYSIS}

Cast A356-T6 aluminum alloys were investigated in this study with varied compositions and processing conditions designated to isolate characteristic microstructural features of the alloys, and study their individual and combined effects on FCG. Chemical composition of the A356 alloys is listed in Table 1. Microstructural characteristics and heat treatment were controlled as follows:

- $\quad \mathrm{T} 6$ heat treated condition (peak strength): solutionized at $540^{\circ} \mathrm{C}$ for 1.5 hours, boiling water quench, natural aging for 12 hours, and artificial aging at $155^{\circ} \mathrm{C}$ for 12 hours;

- two eutectic Si morphologies (unmodified and Sr-modified): eutectic Si modification was achieved by adding Al- $10 \% \mathrm{Sr}$ master alloy to achieve $~ 0.02 \% \mathrm{Sr}$ (the average particle size and aspect ratio are $4.5 \mu \mathrm{m}$ and 0.50 for the unmodified (plate-like) and $1.3 \mu \mathrm{m}$ and 0.88 for the Sr-modified (spheroidal) eutectic Si particles, measured by image analysis);

- one secondary dendrite arm spacing (SDAS; $45 \mu \mathrm{m}$ ): specimens were sand cast with a Cu end chill mold and selected at a specific distance from the chill according to desired SDAS; and

- two grain sizes $(500$ and $1300 \mu \mathrm{m})$ : grain refinement from the original $1300 \mu \mathrm{m}$ to $500 \mu \mathrm{m}$ was achieved by adding Al-5\% Ti-1\% B master alloy to obtain $0.17 \% \mathrm{Ti}, 0.005 \% \mathrm{~B}$.

Table 1. Measured optical emission spectroscopy (OES) and standard Aluminum Association (AA) chemical compositions of the A356 alloy

\begin{tabular}{|l|c|c|c|c|c|c|c|}
\hline Element (\%) & $\mathbf{S i}$ & $\mathbf{F e}$ & $\mathbf{C u}$ & $\mathbf{M n}$ & $\mathbf{M g}$ & $\mathbf{Z n}$ & Al \\
\hline A356 - OES & 6.6 & 0.1 & 0.02 & 0.003 & 0.35 & 0.005 & 92.72 \\
\hline A356 - AA & $6.5-7.5$ & $0.6 \mathrm{max}$ & $0.25 \mathrm{max}$ & $0.35 \mathrm{max}$ & $0.20-0.45$ & $0.35 \max$ & $90.25-93.3$ \\
\hline
\end{tabular}


Long FCG tests were conducted for all alloys according to ASTM E647 standard using compact tension, C(T), specimens with dimensions $63.5 \mathrm{~mm} \times 61.0 \mathrm{~mm} \times 10.0 \mathrm{~mm}$ at $\mathrm{R}=0.1$ stress ratio and $2.5 \mathrm{~mm}$ initial notch size measured from the pin holes. Small FCG tests were done on corner flaw tension, CF(T), specimens with a gage crosssection of $10.2 \mathrm{~mm} \times 5.1 \mathrm{~mm}$, grip cross-section of $20.3 \mathrm{~mm} \times 10.2 \mathrm{~mm}$, and total length $63.5 \mathrm{~mm}$. The notch size was nominally $200 \mu \mathrm{m}$, and experiments were conducted at $\mathrm{R}=0.1$. Both long and small crack growth tests were run at room temperature, relative humidity $20-50 \%$, and cyclic frequency $20 \mathrm{~Hz}$ (except for upper Region III of crack growth, when the frequency was lowered to $10 \mathrm{~Hz}$ to promote stable crack growth). Crack length is measured using the compliance technique for long crack specimens and potential drop method for small crack specimens.

Microstructural characterization of the specimens was carried out using optical and Scanning Election Microscope (SEM), paralleled by to EBSD and Energy Dispersive Spectroscopy (EDS). Fracture surface profile specimens were ground with successively finer grit abrasive paper and polished using $6 \mu \mathrm{m}$ and $1 \mu \mathrm{m}$ diamond paste. The samples were then polished with $0.05 \mu \mathrm{m}$ non-crystallizing colloidal silica for 20 minutes. The EBSD specimen was additionally electrolytically polished in methanol (70\%) and nitric acid (30\%) by volume, while in a liquid nitrogen bath at $12 \mathrm{~V}$ for 60 seconds. This electropolishing technique resulted in good pattern quality from the $\alpha$-Al phase, however lower band contrast from the eutectic Si phase was observed due to different polishing rates. The EBSD specimen was then further prepared by broad beam ion milling for 3 minutes at $1.5 \mathrm{kV}$ discharge voltage and $3 \mathrm{kV}$ acceleration voltage (resulting in an ion beam current of $400 \mu \mathrm{A}$ ) and high quality EBSD patterns were obtained from both phases. EBSD data were collected using a Nordlys EBSD detector and HKL Technology Channel 5 EBSD system interfaced to a Phillips FEI XL30 SEM. The SEM operating voltage used was $20 \mathrm{kV}$ to optimize the quality of the diffraction patterns. Post-processing analysis was conducted using standard HKL-EBSD Channel 5 software package and with MATLAB MTEX toolbox. High-resolution imaging and EDS analysis were performed on a JOEL 7800F FEG-SEM equipped with AZTEC data acquisition and analysis software.

\section{BEHAVIOR OF LONG AND SMALL FATIGUE CRACKS CHARACTERIZED BY TRADITIONAL FRACTOGRAPHIC TECHNIQUES}

Fatigue crack growth behavior of all material conditions has been systematically studied with optical and electron microscopy in order to elucidate crack-microstructure interaction mechanisms at different growth stages from threshold to Region III. Mechanisms of long FCG will be discussed first, followed by the effects on FCG behavior due to microstructural variants, and then the differences in mechanisms of MSCs will be addressed.

\subsection{Changes in long fatigue crack growth mechanisms with applied driving force}

Fracture surface profiles (cross-sections of the failed specimens) for A356-T6 alloys with different microstructural conditions are shown in Figure 1 for different $\Delta \mathrm{K}$ levels. In all cases, crack propagation at low driving force $(\Delta \mathrm{K})$ is predominantly crystallographic cleavage through the $\alpha$-Al matrix, then changes to mixed-mode with combined crystallographic propagation and interactions with eutectic Si particles at intermediate driving force, and finally propagation occurs primarily along/through $\mathrm{Si}$ particles at high driving force.

It was observed that the failure mechanism of the eutectic Si (debonding or fracture) is affected by both particle morphology and applied stress intensity, and illustrations of the different mechanisms are depicted in Figure 2. At low $\Delta \mathrm{K}$, the failure mechanism for unmodified eutectic $\mathrm{Si}$ is dependent on the orientation of the Si plates relative to the crack plane. Plates with the principal axis perpendicular to the crack plane fracture because of the resistance to debonding provided by the large interfacial area parallel to the loading direction, and vice versa. At intermediate angles, a transition from debonding to fracture occurs when the particles are oriented around $45^{\circ}$ with respect to the crack plane. At high stress intensity, fracture is the dominant mechanism independent of particle orientation. In the Sr-modified condition, the crack predominantly debonds Si particles from the $\alpha$-Al matrix at low stress intensity (Region I and lower Region II) and fractures particles at high stress intensity (upper Region II and Region III). 
Several researchers have investigated in depth the transition in failure mode between debonding and fracture for $\mathrm{Sr}$-modified eutectic Si. Gall et al. [25] found that Sr-modified eutectic Si particles are fractured ahead of the crack tip at $\Delta \mathrm{K}>6 \mathrm{MPa} \sqrt{\mathrm{m}}$ for an A356-T6 alloy. Lados et al. [12] also observed predominantly fracture of Sr-modified eutectic Si particles at $\Delta \mathrm{K}>5.5 \mathrm{MPa} \sqrt{\mathrm{m}}$ for $\mathrm{Al}-7 \% \mathrm{Si}-0.45 \% \mathrm{Mg}$. A model to predict the transition stress intensity was developed by Spangenberger and Lados [26] based on hardness indentation measurements to quantify the competing energy release rates of debonding and fracture. In this work, it was predicted that the failure mode transition is dependent on the morphology of the Si phase, and occurs at a value of $\Delta \mathrm{K} \sim 6 \mathrm{MPa} \sqrt{\mathrm{m}}$. Experimentally, the transition from debonding to fracture was observed on the crack surface to occur at a stress intensity of $\Delta \mathrm{K}=5.4 \mathrm{MPa} \sqrt{\mathrm{m}}$.

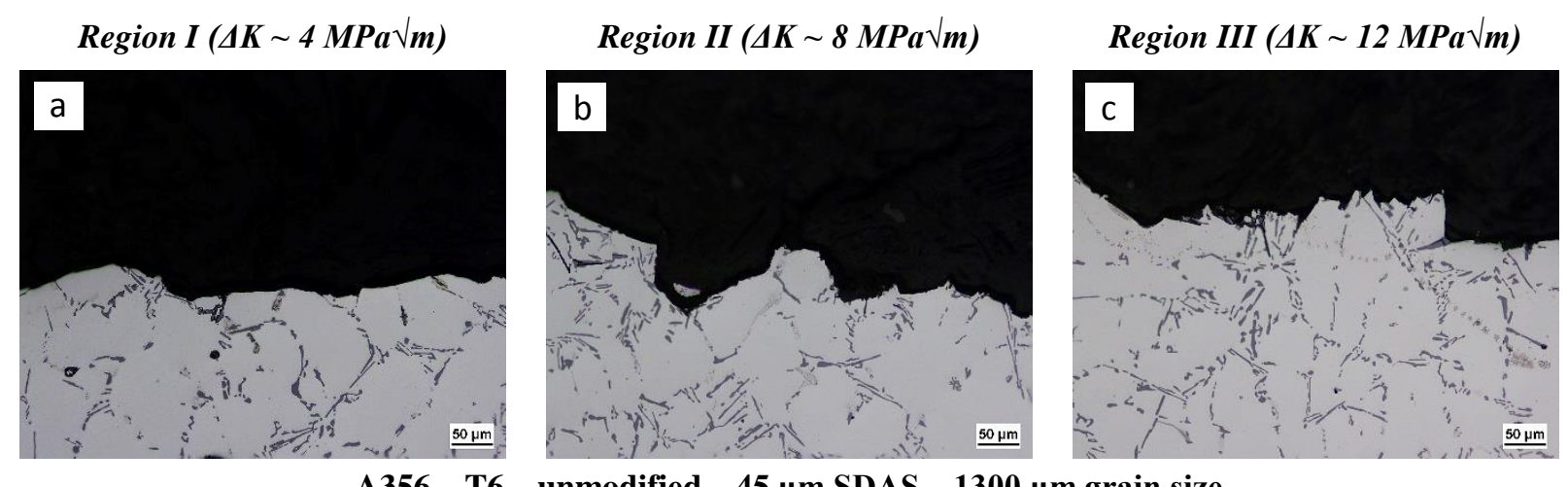

A356 - T6 - unmodified - $45 \mu \mathrm{m}$ SDAS - $1300 \mu \mathrm{m}$ grain size
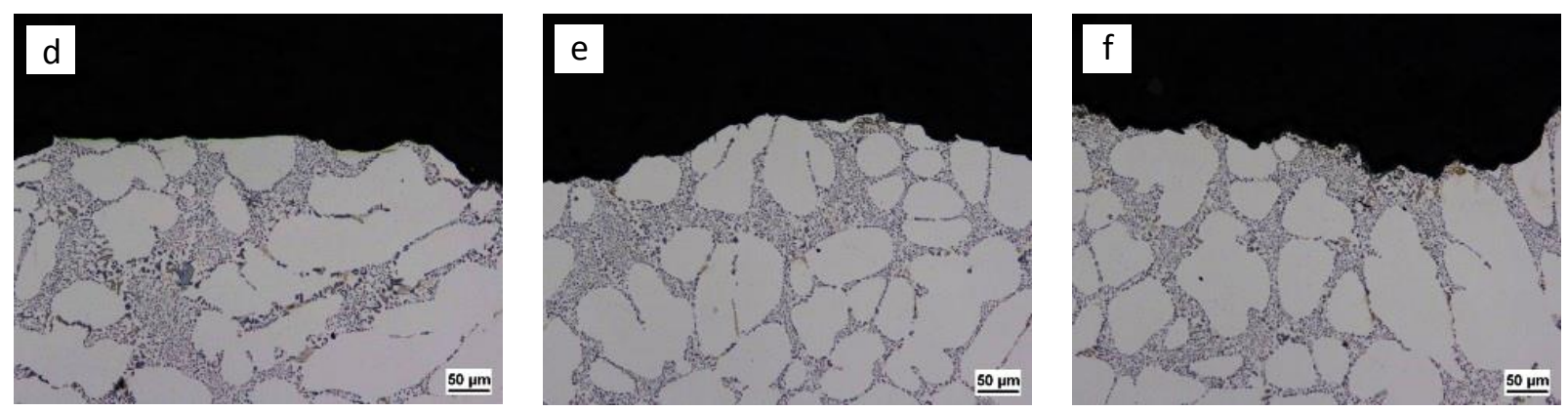

A356 - T6 - Sr-modified - $45 \mu \mathrm{m}$ SDAS - $1300 \mu \mathrm{m}$ grain size
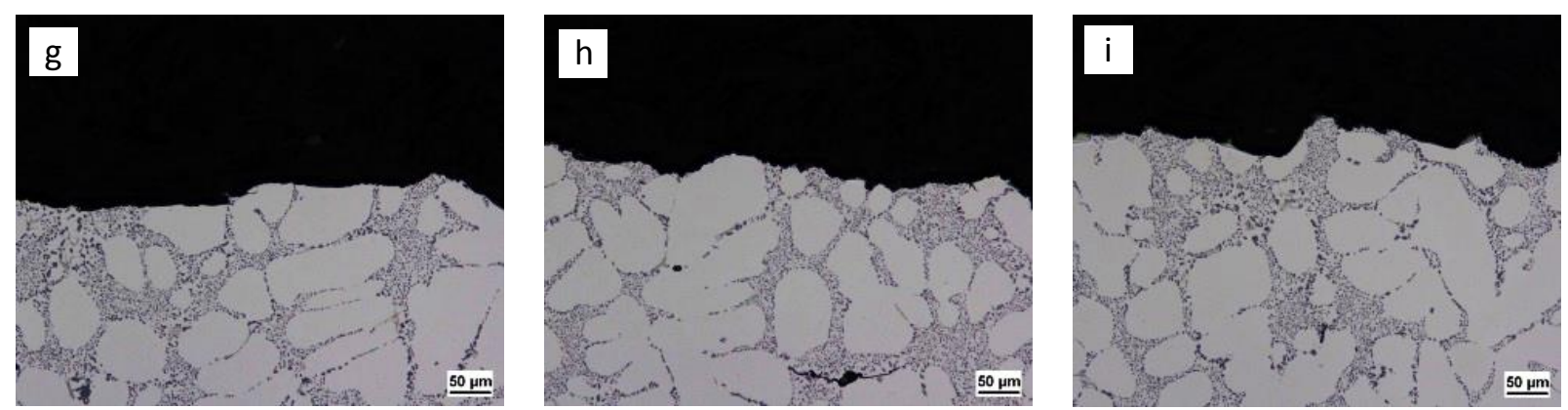

A356 - T6 - Sr-modified - $45 \mu \mathrm{m}$ SDAS - $500 \mu \mathrm{m}$ grain size

Figure 1. Fracture surface profiles at $\mathrm{R}=0.1$ for A356-T6 alloys with various microstructural conditions. 


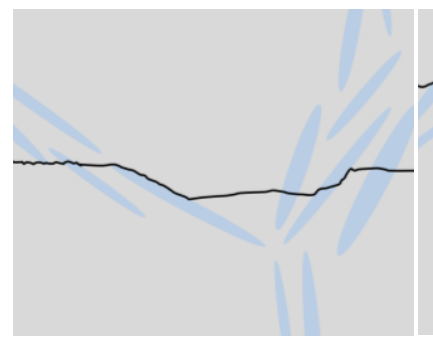

(a)

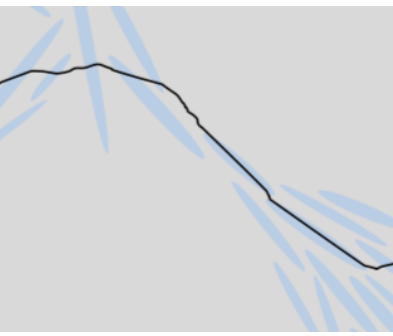

(b)

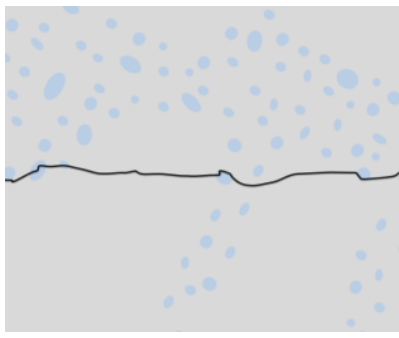

(c)

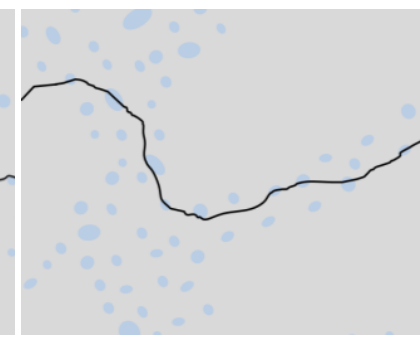

(d)

Figure 2. Eutectic Si particle failure modes for unmodified and $\mathrm{Sr}$-modified alloys at $(\mathrm{a}, \mathrm{c})$ low $\Delta \mathrm{K}$ and $(\mathrm{b}, \mathrm{d})$ high $\Delta \mathrm{K}$.

Given that mechanisms of crack propagation in cast alloys are affected by microstructural constituents smaller than the grain size (i.e., eutectic Si morphology/distribution), A356-T6 alloys have been studied with respect to both eutectic Si morphology (unmodified and Sr-modified) and grain size (500 and $1300 \mu \mathrm{m})$. Fatigue crack growth results comparing all conditions are shown in Figure 3. Figure 3(a) shows FCG data from the specimens depicted in Figures 1(a-c,d-f), and indicates that Sr-modification improves low cycle fatigue behavior by increasing the fracture toughness (from 17.3 $\mathrm{MPa} \sqrt{\mathrm{m}}$ to $25.2 \mathrm{MPa} \sqrt{\mathrm{m}}$ ). This occurs due to geometric effects, where angular, plate-like eutectic Si particles in the unmodified condition create stress concentrations that facilitate crack advance, in contrast with spherical Sr-modified Si particles which better dissipate energy away from the crack tip and transfer stresses off of the matrix. In Figure 3(b), comparing the specimens in Figures 1(d-f,g-i), the effects of grain size can be seen, indicating that the larger grain size material has a higher crack growth threshold. This occurs because the coarsegrained material has fewer and larger intergranular junctions over which the Si particles are distributed, therefore causing larger crack deflections due to interactions with more heterogeneously distributed clusters (increased roughness-induced closure), and thus a higher FCG threshold, $\Delta \mathrm{K}_{\text {th }}\left(4.1 \mathrm{MPa} \sqrt{\mathrm{m}}_{\mathrm{vs}}\right.$. 5.1 MPa $\left.\sqrt{\mathrm{m}}\right)$.

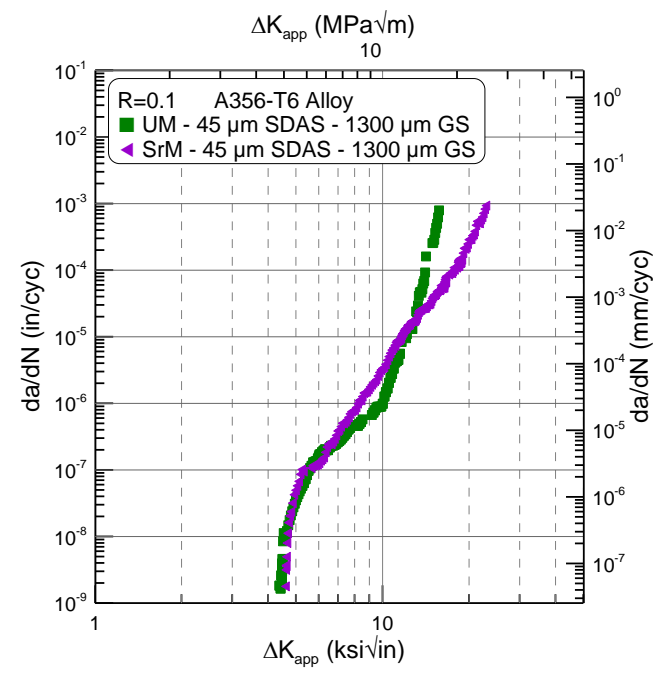

(a)

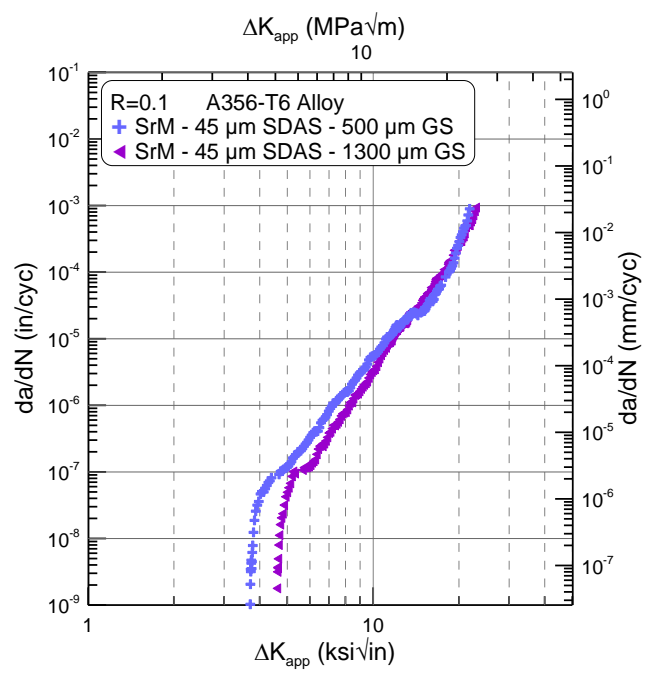

(b)

Figure 3. Long FCG data for A356-T6 alloys comparing effects of (a) Sr-modification and (b) grain refinement.

Fracture surface roughness was further characterized by image analysis techniques to provide insight into closure mechanisms for both grain size conditions. Peak-to-valley roughness $\left(\mathrm{R}_{\mathrm{t}}\right)$ was calculated along the fracture surface profile after subtraction of tilt/waviness components in order to separate microstructural and macroscopic roughness components. Roughness and $\mathrm{K}_{\text {closure }}\left(=\mathrm{K}_{\max }-\Delta \mathrm{K}_{\mathrm{ACR}}\right)$ were averaged between crack lengths corresponding 
to $\Delta \mathrm{K}=6.6 \mathrm{MPa} \sqrt{\mathrm{m}}(6 \mathrm{ksi} \sqrt{ } \mathrm{in})$ down to the respective crack growth thresholds for each alloy (concentrating on Region I of crack growth, which is strongly affected by closure phenomena), Figure 4 . The magnitudes of the roughness and closure are dependent on the intrinsic microstructure of the alloy, as lower roughness/closure is observed for the material with $500 \mu \mathrm{m}$ grain size compared to the $1300 \mu \mathrm{m}$ grain size alloy. The decrease in roughness/closure with grain refinement is due to the more homogeneous eutectic Si particle/colony distributions (in accordance with the crack propagation mechanisms described in the preceding paragraph), which cause smaller crack deflections.

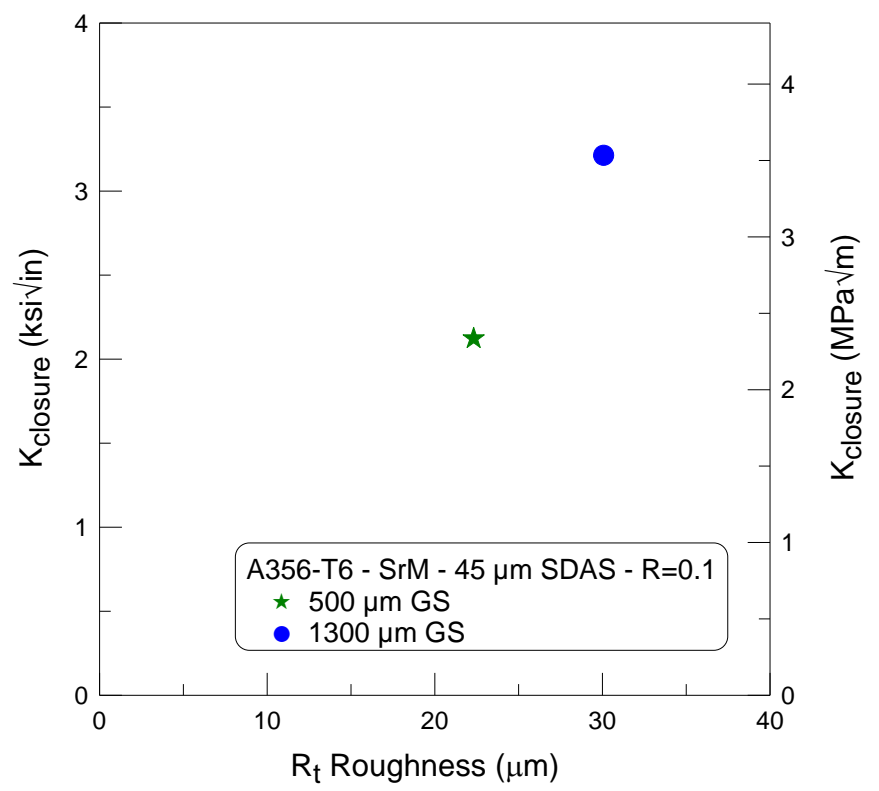

Figure 4. Measurements of average roughness and closure for A356-T6 - Sr-Modified - $45 \mu \mathrm{m}$ SDAS alloy with two grain sizes.

\subsection{Microstructural effects on small fatigue crack growth behavior and mechanisms}

Small FCG behavior has also been experimentally evaluated for A356-T6 with two different grain sizes (Srmodified, $45 \mu \mathrm{m}$ SDAS, 500 and $1300 \mu \mathrm{m}$ grain size; $200 \mu \mathrm{m}$ initial flaw size). A comparison between small and long FCG data is shown alongside corresponding SEM fractographic images in Figure 5. The MSC growth data for the $500 \mu \mathrm{m}$ grain size alloy are shown in Figure 5(a). Inflections in the FCG curve (acceleration/deceleration) can be seen at crack growth rates of $3 \times 10^{-7}$ and $2 \times 10^{-6} \mathrm{~mm} / \mathrm{cycle}$, and are attributed to the crack's interactions with intergranular regions containing eutectic Si colonies observed on the fracture surface at the corresponding crack lengths, Figures 5(c,e), and will be discussed in detail in Section 4.2 with the aid of EBSD. Crack propagation is crystallographic cleavage through dendritic cells in the primary $\alpha$-Al matrix (cleavage planes), and mixed cleavage of eutectic $\mathrm{Al}$ with localized plasticity around eutectic Si particles (dimpling and void growth within the matrix, leading to debonding/fracture of the eutectic Si particles), Figure 6. Similar mechanisms of crack propagation were also observed for the large grain size alloy, Figures $5(\mathrm{~b}, \mathrm{~d}, \mathrm{f})$, where deceleration was again found to correspond to the crack's interactions at intergranular spaces containing grain boundaries and $\mathrm{Si}$ colonies. The respective effects of each of these features will be investigated in greater depth in Section 4.2 using EBSD. Ultimately, FCG resistance in early growth stages is enhanced by smaller grain size, because there are an increased number of deceleration interactions and of greater magnitude, favoring high cycle fatigue behavior. 


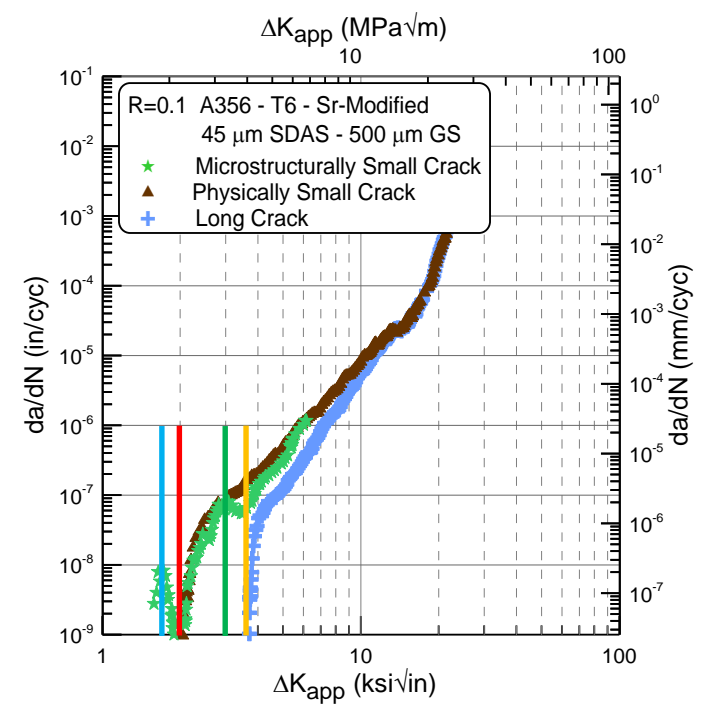

(a)

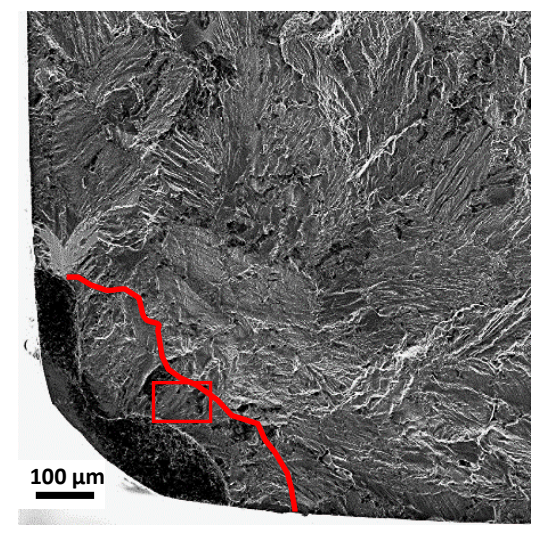

(c)

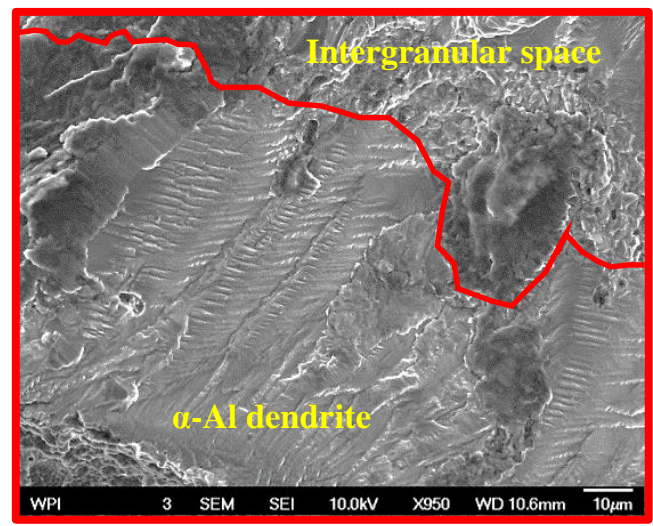

(e)

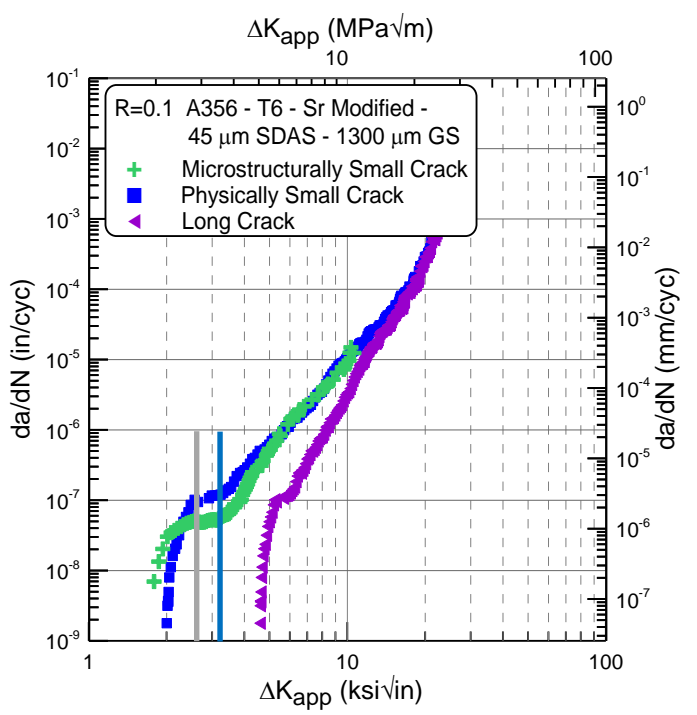

(b)

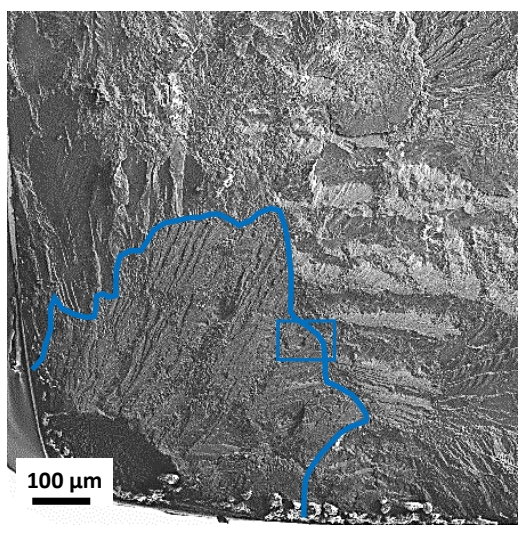

(d)

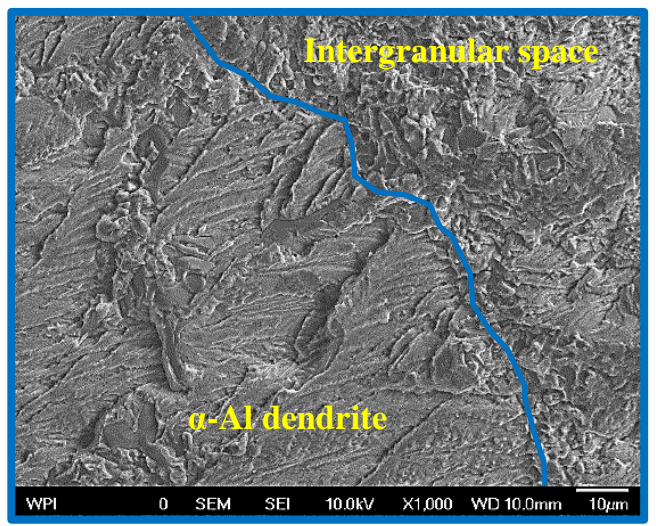

(f)

Figure 5. Small versus long FCG data at $\mathrm{R}=0.1$ and fractographs showing MSC-microstructure interactions for A356 - T6 - Sr-Modified - $45 \mu \mathrm{m}$ SDAS (a,c,e) $500 \mu \mathrm{m}$ and (b,d,f) $1300 \mu \mathrm{m}$ grain size. Red and blue contours indicate the location of the crack front corresponding to acceleration/deceleration. 


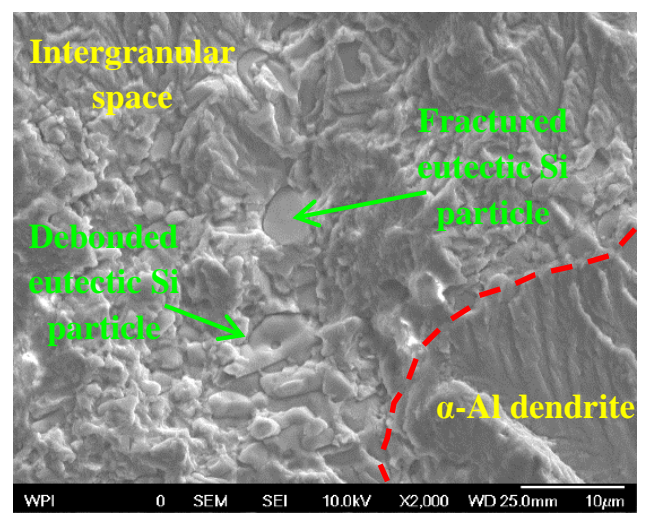

Figure 6. Change in local MSC growth mechanisms from crystallographic cleavage in the primary $\alpha$-Al dendrite to combined debonding/fracture of Si particles with mixed void coalescence and quasi-cleavage of the eutectic Al. Crack growth is from lower right to upper left; the red line indicates the primary Al dendrite cell boundary.

\section{INVESTIGATION OF FATIGUE CRACK GROWTH MECHANISMS BY ELECTRON BACKSCATTER DIFFRACTION}

From fractographic studies alone, it cannot be completely understood to what extent the secondary eutectic $\mathrm{Si}$ particles and grain boundaries control crack growth, and the role grains' crystallographic orientations play on the overall crack path. To complement the investigation of FCG behavior done by traditional fractographic techniques, further EBSD studies were conducted to evaluate the effects of grain orientation, grain's Schmid factor, and grain boundary characteristics (i.e., twist or tilt), and to investigate the relative influence of the Si phase and grain boundaries on small and long crack paths.

\subsection{Changes in small and long crack growth mechanisms with applied driving force and grain orientation}

The effect of grain orientation on small and long FCG behavior was studied for the A356-T6 alloy depicted in Figures 5(a,c,e) (Sr-modified, $45 \mu \mathrm{m}$ SDAS, $500 \mu \mathrm{m}$ grain size, $\mathrm{R}=0.1$; initial flaw size is $200 \mu \mathrm{m}$ ) by combined EBSD/EDS. The 2D scans were taken immediately below the specimen surface along the profile of the crack path in order to reveal crack interactions with the grain structure and assess crystallographic texture. Figure 7 shows the fracture surface profile with various post-processing operations: (a) backscattered electron image, (b) Schmid factor for the $\{111\}\langle 0 \overline{1} 1\rangle$ system relative to far-field loading axis (vertical axis), (c) grain boundary twist, and (d) grain boundary tilt. Four marked areas were studied with high-magnification EBSD, the first corresponding to the deceleration event at $\Delta \mathrm{K}=3.0 \mathrm{MPa} \vee \mathrm{m}$, and the other three related to events in the region of transition to the long FCG regime. The Schmid factor $(\mathrm{m})$ relates the far-field applied load to the crystallographic shear stress applied on each grain, and is the ratio of the crystallographic shear stress to the applied stress, Eq. (1). The Schmid factor ranges from 0 to 0.5 , and is the fraction of the nominal applied load transferred into crystallographic shear stress, representing resistance to plastic slip of an individual grain (lower values represent hard grains that resist deformation and higher values correspond to soft grains).

$$
m=\tau / \sigma=\left(\left[N_{i}\right][L]\right)\left(\left[D_{i}\right][L]\right)
$$

It can be seen in Figure 7(b) that the MSC alternately traverses low and high Schmid factor grains, whereas in the long crack regime it mostly propagates through softer (high Schmid factor) grains. This observation is explained by the fact that the small crack has insufficient energy to change direction, and simply grows through the grains immediately ahead of it, regardless of their crystallographic orientation. In contrast, the long crack is better able to change direction due to its larger plastic/damage zone (ability to select from a larger volume of material), and therefore it selects overall higher Schmid factor grains to minimize energy expenditure. 


\section{Crack Growth Direction}

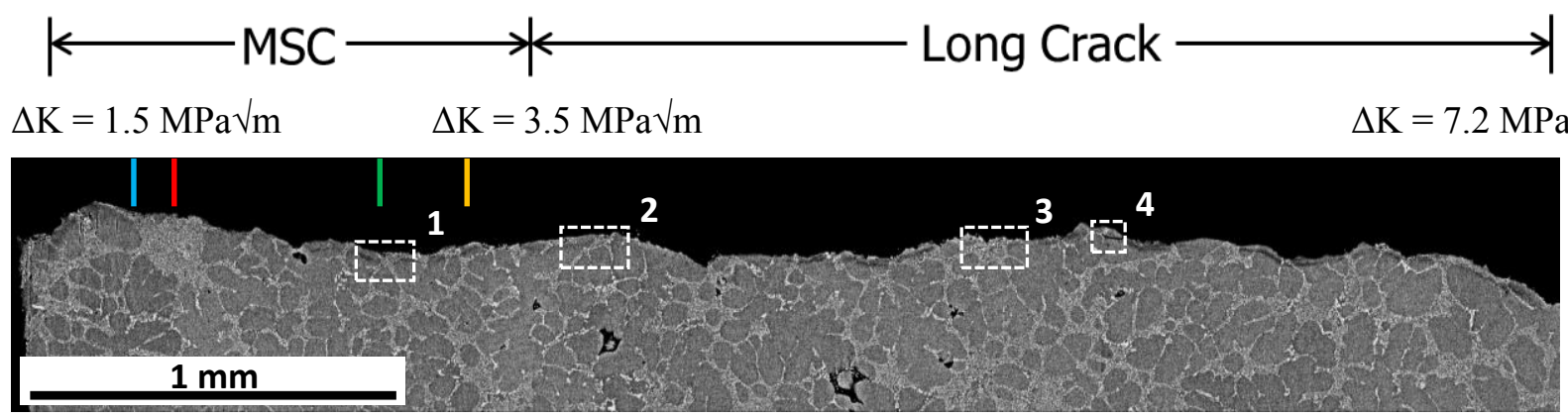

(a)

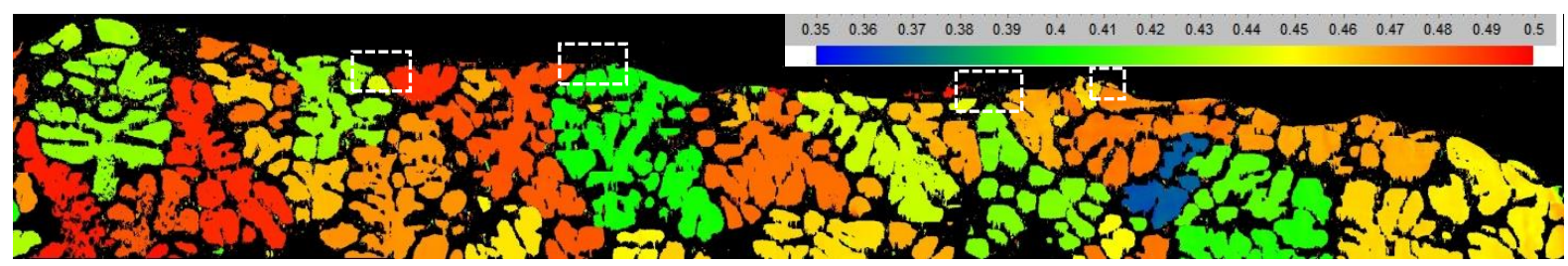

(b)

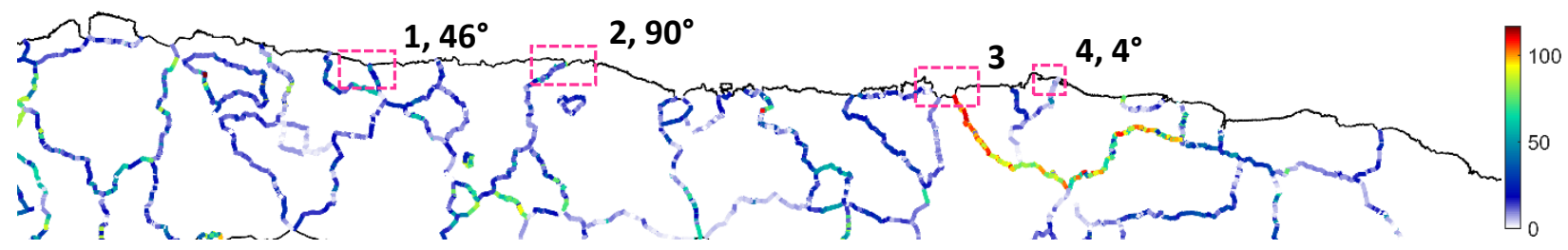

(c)

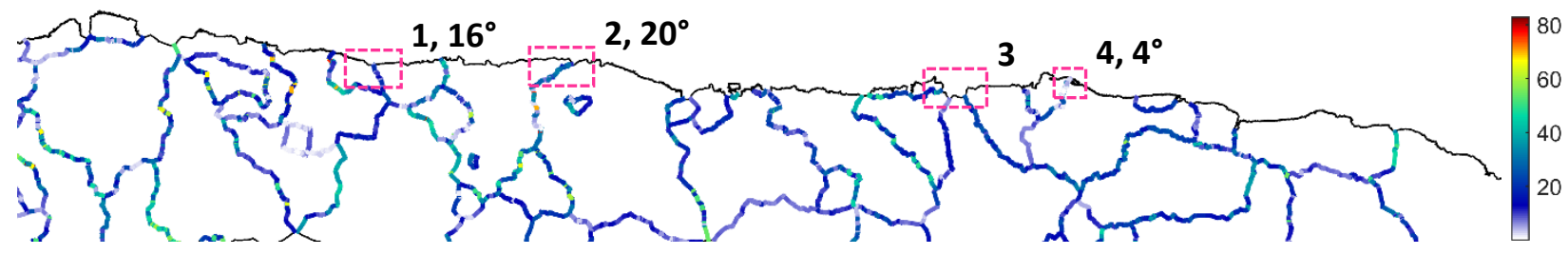

(d)

Figure 7. A356-T6 - Sr-modified - $45 \mu \mathrm{m}$ SDAS - $500 \mu \mathrm{m}$ GS fracture surface profiles: (a) backscattered electron image, (b) $\{111\}\langle 0 \overline{1} 1\rangle$ Schmid factor map relative to loading direction (vertical axis, normal to the crack plane), (c) grain boundary twist, and (d) grain boundary tilt. No twist/tilt angle was calculated for Area 3 due to its location at a four-grain eutectic junction.

Grain boundary tilt and twist angles are shown in Figures 7(c,d), and are calculated according to Eqs. (2) and (3) as depicted schematically in Figure 8. The calculations assume that the crack approaches the grain barrier/boundary in grain 1 (left side of boundary) on the plane with the highest resolved shear stress (Schmid factor) and $\alpha / \beta$ is taken to be the minimum for the $\{111\}$ system of grain 2 (right side of boundary). Note that because only surface measurements are used, the grain boundary plane orientation is not known in 3D. It is assumed here that most grains are sufficiently large that the out-of-plane component of the grain boundary orientation is approximately zero and $\mathrm{E}$ is the surface trace (this is a reasonable assumption given that the grain size of the material is $500 \mu \mathrm{m})$. Figures $7(\mathrm{c}, \mathrm{d}$ ) 
indicate that most of the boundaries intercepted in the MSC regime have relatively low twist and tilt components, and the interactions with specific microstructural barriers in this region will be discussed subsequently in Section 4.2. In the long crack growth regime, the crack crosses several high angle boundaries (twist/tilt $>50^{\circ}$ ) with no apparent crystallographic influence on crack growth. This observation is supported by the crack-microstructure interactions described in Section 3.1., as the crack path is known to be most significantly influenced by the eutectic Si particles' morphology and distribution at high stress intensity (i.e., crack growth is primarily controlled by secondary phases smaller than the grain size).

$$
\begin{aligned}
& \alpha=\cos ^{-1}\left(\left([E] \times\left[N_{1}\right]\right) \cdot\left([E] \times\left[N_{2}\right]\right)\right) \\
& \beta=\cos ^{-1}\left(\left(\left[N_{1}\right] \times\left([E] \times\left[N_{1}\right]\right)\right) \cdot\left(\left[N_{2}\right] \times\left([E] \times\left[N_{2}\right]\right)\right)\right)
\end{aligned}
$$

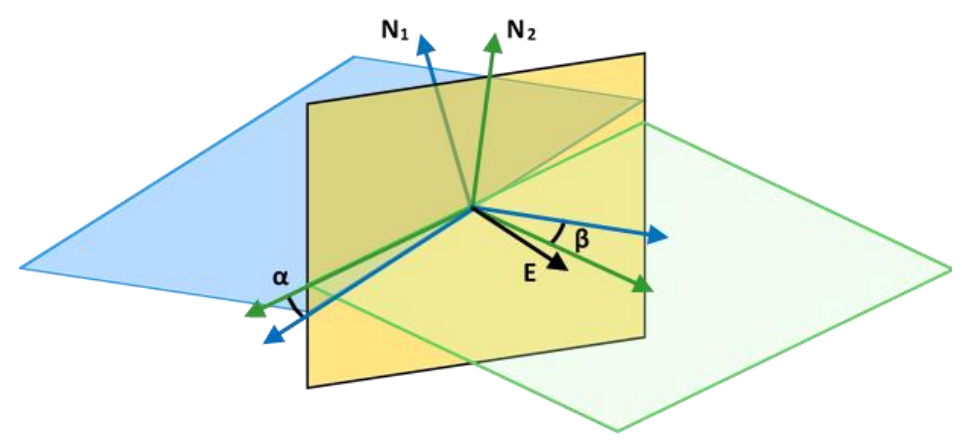

Figure 8. Schematic diagram for the determination of twist angle $(\alpha)$ and tilt angle $(\beta) . N_{1}$ and $N_{2}$ denote the normals to the first and second grain slip systems, and $\mathrm{E}$ is the normal to the grain boundary plane.

\subsection{Fatigue crack interactions with eutectic silicon colonies and grain boundaries}

In order to understand the role of the microstructure on FCG mechanisms, the unique microstructure of this alloy must first be discussed. It has been established in the literature (Shankar et al., [27, 28]) that Sr additions significantly alter the solidification behavior in this alloy system, and will be described briefly here as its effects relate to the mechanisms of FCG. During solidification, primary $\alpha$-Al dendrites will be the first phase to solidify. The addition of $>50 \mathrm{ppm}$ Sr interferes with $\mathrm{Si}$-Si covalent bonding such that solidification of the eutectic Si phase is suppressed below the equilibrium eutectic temperature, and the liquid ahead of the solidification front is supercooled. The liquid becomes supersaturated with Si until it nucleates as blocky Si crystals along the primary Al dendrite tips (taking particular crystallographic relationships, e.g. [125]Al || [114]Si and [114]Al || [111]Si), and blocking mass feeding of the dendrites and halting their growth. The remaining interdendritic liquid is then at the equilibrium eutectic composition and eutectic $\mathrm{Al}$ and $\mathrm{Si}$ grow competitively until they impinge on each other. The net effect of this process is to produce large primary $\mathrm{Al}$ grains/dendrites and a complex interdendritic structure consisting of fibrous, highly twinned eutectic Si and fine-grained eutectic Al. The fibrous eutectic Si can further break down during solution treatment $\left(\sim 540^{\circ} \mathrm{C}\right)$ into spherical crystals. [29] This unique microstructure gives rise to a complex interplay of phenomena, which have been studied using high-magnification EBSD. 


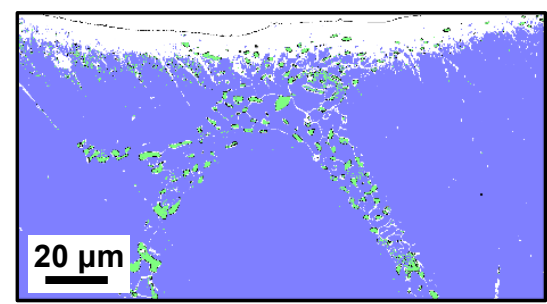

(a)

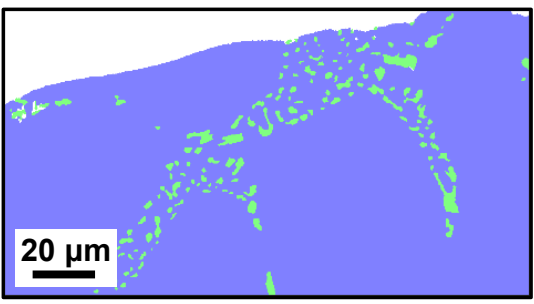

(d)

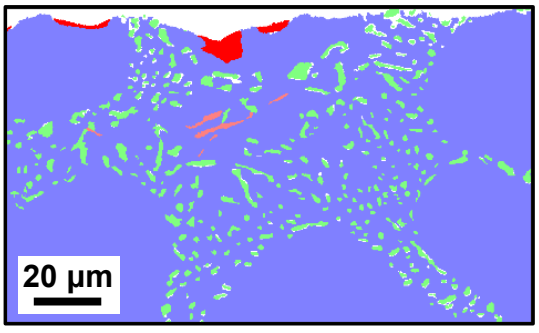

(g)

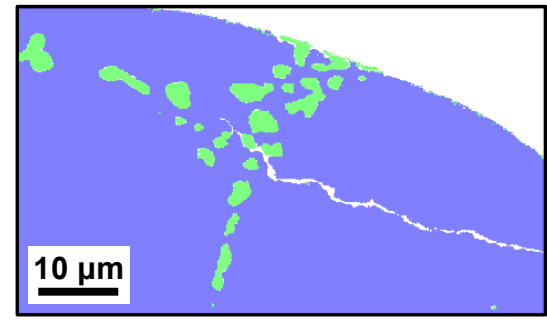

(j)

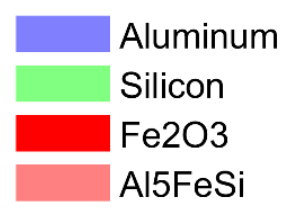

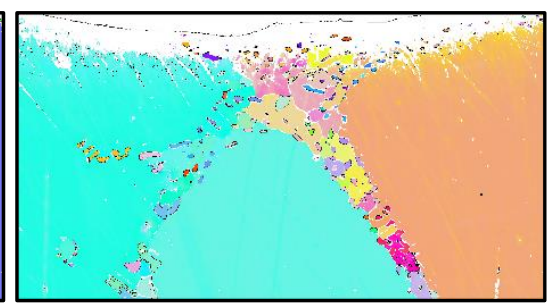

(b)

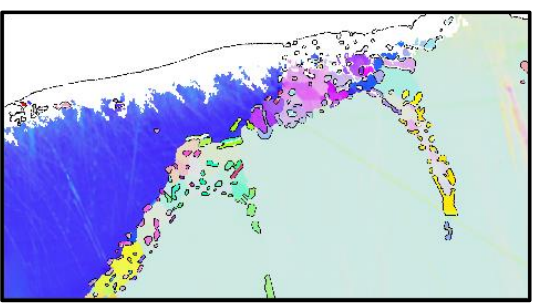

(e)

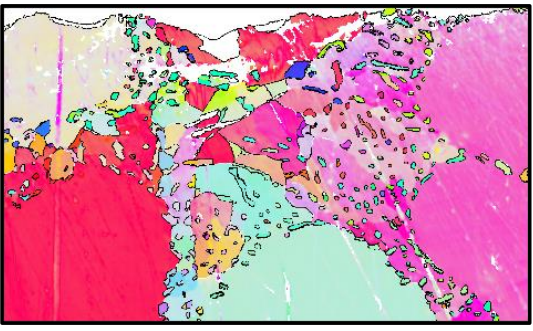

(h)

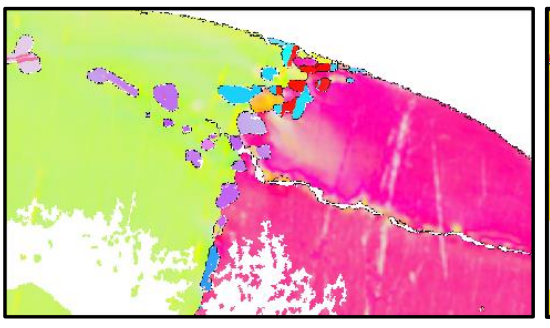

(k)

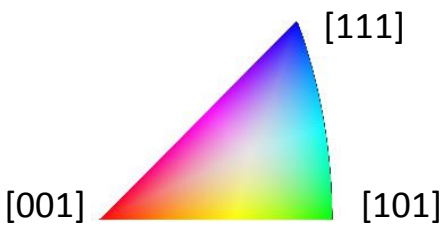

101]

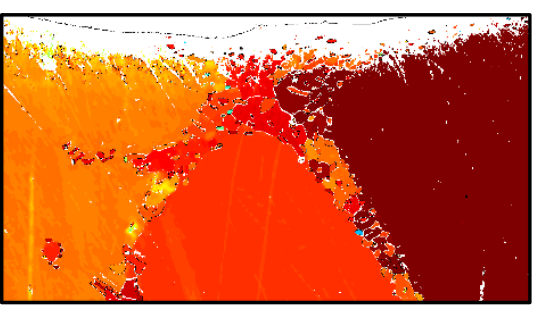

(c)

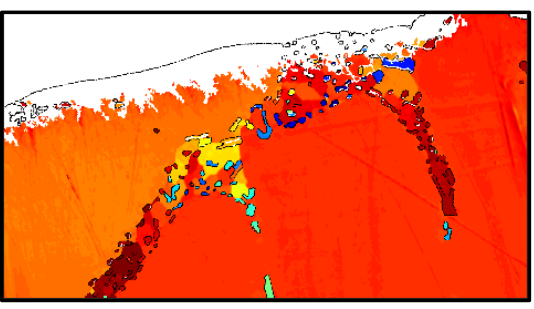

(f)

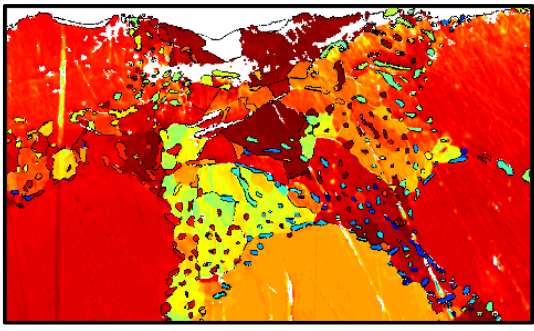

(i)

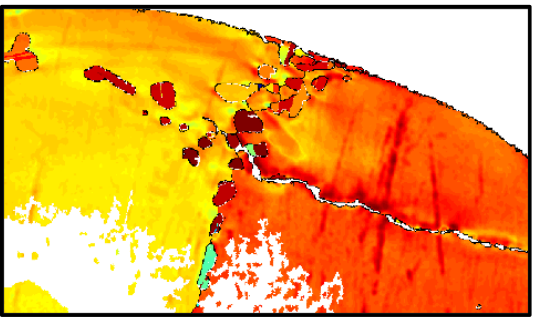

(1)

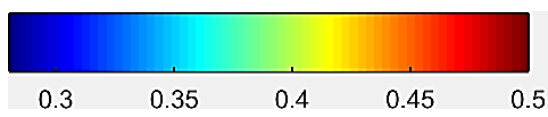

Figure 9. High magnification maps of the Areas 1-4 marked in Figure 7. The left column is the phase map, the center column is IPF coloring, and the right column is Schmid factor. Nominal stress intensity is: $(\mathrm{a}-\mathrm{c}) \Delta \mathrm{K}=3.0$ $\mathrm{MPa} \sqrt{\mathrm{m}},(\mathrm{d}-\mathrm{f}) \Delta \mathrm{K}=3.6 \mathrm{MPa} \sqrt{\mathrm{m}},(\mathrm{g}-\mathrm{i}) \Delta \mathrm{K}=5.0 \mathrm{MPa} \sqrt{\mathrm{m}},(\mathrm{j}-\mathrm{k}) \Delta \mathrm{K}=5.4 \mathrm{MPa} \sqrt{\mathrm{m}}$. Crack growth is from left to right.

Figure 9 depicts high-magnification EBSD images for the regions of interest (Areas numbered 1-4 in Figure 7(a)) in EDS/phase, Inverse Pole Figure (IPF), and Schmid factor mappings. Note that the edge of the sample was not resolved in some cases due to differences in sample preparation and was reconstructed from EDS data as indicated by the contour line. As discussed previously, it is apparent in Figures 9(b,e,h) that the primary Al grains share a common crystallographic relationship with the fine grained eutectic $\mathrm{Al}$, and that Si particles form "family" groups which have common crystallographic orientations (indicated by similar color groupings). Figures 9(a-c) were taken at a crack 
length corresponding to a deceleration event in Region I of crack growth (Figure $7(\mathrm{a}), \Delta \mathrm{K}=3.0 \mathrm{MPa} \sqrt{\mathrm{m}}$ ), associated with the crack passing through an intergranular colony of eutectic Si and Al. Within the intergranular space, the crack deflects from a linear path, tracing Si particles, and developing a more tortuous crack path through the intergranular colony than through the primary $\alpha-\mathrm{Al}$ matrix. The crack selects this path for two reasons: 1 ) the right-hand grain has a high Schmid factor and thereby transfers stress onto the eutectic phase (to be discussed subsequently) and 2) the boundary twist angle is $46^{\circ}$, which represents a significant barrier to slip across grain boundaries, and thereby to crack propagation. This crystallographic misalignment, in conjunction with the blocking effect of the eutectic phases, dictates the considerable magnitude of deceleration observed in Figure 7(a). Crack growth in Area 2 ( $\Delta \mathrm{K}=3.6$ $\mathrm{MPa} \sqrt{\mathrm{m}}$ ), in a physically-small crack regime in the transition to long crack, is similarly controlled by the greater Schmid factor of the right-hand grain, Figures 9(d-f). Stresses are transferred onto the eutectic Si phase by the high Schmid factor parent grain, and the crack consequently follows a narrow ligament of the eutectic Si colony.

Figures $9(\mathrm{~g}-\mathrm{i})$ and $9(\mathrm{j}-1)$, Areas 3 and 4 , were taken at $\Delta \mathrm{K}=5.0$ and $5.4 \mathrm{MPa} \sqrt{\mathrm{m}}$, respectively. Area 3 corresponds to a four-grain junction containing a large intergranular eutectic colony. At this low applied stress intensity, the colony would typically provide significant resistance to crack growth and the crack should predominantly propagate through the $\alpha$-Al matrix with only opportunistic interactions with the eutectic Si phase. Here, however, several brittle $\mathrm{Fe}_{2} \mathrm{O}_{3}$ particles are present in high Schmid factor grains, causing stress to transfer onto and break the iron phase particles. The resistance of the large eutectic colony (analogus to what was observed in Area 1) was not effective in this case due to the presence of the brittle Fe phase in grains well-oriented for slip, which control the crack path through the adjacent eutectic colonies in Area 3. In Area 4, Figures 9(j-1), a secondary crack is shown to grow through the sectioning plane (entering the plane from the center of the image and growing from left to right). This secondary crack debonds two Si particles, and then propagates through the matrix before linking up with the primary crack. Crack bifurcation is promoted by the anisotropy of elastic behavior of the neighboring grains and eutectic Si particles, concentrating stresses along particle boundaries and nucleating microcracks. Formation of new cracks then helps to distribute the applied stresses between multiple crack tips and lower the effective crack driving force on the main crack. This mechanism is supported by observation of the orientation gradient within the right-hand grain in Figures $9(\mathrm{k}, \mathrm{j})$ indicating the presence of local misorientations due to changes in lattice spacing caused by crack-microstructure interactions. Small lobes of local strains can be observed between Si particles, and a large lobe in the center of the images occured due to combined geometric stress concentrations and dissimilarities in elastic material properties at the $\mathrm{Al} / \mathrm{Si}$ interfaces.

Comparison of Figures $9(\mathrm{~g}-\mathrm{i})$ and $8(\mathrm{j}-1)$, having similar stress intensity and different intergranular eutectic colony size, indicates the role of the colony in stress homogenization/dissipation. In the case of the large colony, Figures 9(gi), the applied stresses are well distributed across the network of eutectic Si particles and Al grains, and the stress lobes are not present (however the colony strength is still limited in this case by the iron phase particle in Area 3). In contrast, in the presence of the small colony in Figures $9(\mathrm{j}-1)$, there is an insufficient number of particles over which to distribute stresses, and plastic deformation of the matrix occurs in lobe formation and damage occurring at $\mathrm{Al} / \mathrm{Si}$ interfaces. From this, it can be concluded that increasing the size of intergranular colonies of eutectic Si and finegrained $\mathrm{Al}$ will in general increase the FCG resistance in early growth stages, by diffusing applied stresses away from the crack tip and onto the reinforcing eutectic phases. The barrier effect diminishes as $\Delta \mathrm{K}$ increases and the plastic zone becomes larger, changing the FCG mechanisms from the primary $\alpha$-Al matrix (strengthened by Si in early growth stages) to increasingly weaker eutectic Si particles/interfaces at higher $\Delta \mathrm{K}$ levels, as observed in Figure 1.

\subsection{Stress redistribution analysis around eutectic silicon particles}

In order to better understand the relative role of grain boundaries and Si particles in controlling crack path selection, computational modeling studies have been conducted to analyze stress redistribution around particles. For small cracks, grain boundaries are known to block slip during crack propagation and increasing the number of interactions (i.e., smaller grain size) will enhance overall fatigue lifetime. Conversely, for long cracks, small grain size lowers the crack growth threshold due to lower crack closure, a mechanism described in Section 3.1. However, 
it also needs to be clarified how stresses are redistributed by the eutectic Si phase: whether it locally stiffens the intergranular region (transferring stresses off of the matrix and shielding it) or it provides regions of enhanced damage (nucleating microcracks and reducing FCG lifetime).

In order to investigate the effect, two dimensional plane strain, isotropic elasticity simulations of a circular $\mathrm{Si}$ particle $\left(\mathrm{E}_{\mathrm{Si}}=170 \mathrm{GPa}, v_{\mathrm{Si}}=0.25\right)$ embedded in an $\mathrm{Al}$ matrix $\left(\mathrm{E}_{\mathrm{Al}}=70 \mathrm{GPa}, v_{\mathrm{Al}}=0.33\right)$ with a perfectly bonded interface were conducted to determine stress distributions around the particle due to a far-field applied load (along the vertical axis). Figure 10 shows the normalized stresses (i.e., stress concentration factors) for the radial, angular, and von Mises stresses, and the results agree well with analytical solutions, Eqs. (4-7), where $\alpha_{i}=1-v_{i} ; \gamma=\mu_{2} / \mu_{1} ;$ and 1,2 correspond to the matrix and particle. [30] The radial stress component, Figure 10(a), indicates that there is a cap on the particle along the axis of the applied stress which experiences stresses normal to the interface exceeding the farfield applied load (maximum stress concentration at the interface $=1.21$ ), facilitating debonding of the particle from the matrix. The angular stress component, Figure 10(b), shows that the presence of the particle shields the matrix from opening loads in the directions normal to the far-field applied stress, however the particle experiences significantly higher stresses (maximum stress concentration in the particle $=1.25$ ), which can enable particle fracture, especially in the presence of a well-oriented twin plane. The von Mises stress plot corroborates Figures 10(a,b) and shows that stress is concentrated primarily in the fan centered on the particle along the axis of the applied stress.

$$
\begin{aligned}
\sigma_{r r}^{1} & =\frac{\sigma}{2}\left\{1+\frac{1+2 \alpha_{1} \gamma-2 \alpha_{2}-\gamma}{2 \alpha_{2}+\gamma-1}\left(\frac{a}{r}\right)^{2}+\left[1-\frac{4(1-\gamma)}{1-\gamma+4 \alpha_{1} \gamma}\left(\frac{a}{r}\right)^{2}+\frac{3(1-\gamma)}{1-\gamma+4 \alpha_{1} \gamma}\left(\frac{a}{r}\right)^{4}\right] \cos (2 \theta)\right\} \\
\sigma_{\theta \theta}^{1} & =\frac{\sigma}{2}\left\{1-\frac{1+2 \alpha_{1} \gamma-2 \alpha_{2}-\gamma}{2 \alpha_{2}+\gamma-1}\left(\frac{a}{r}\right)^{2}-\left[1+\frac{3(1-\gamma)}{1-\gamma+4 \alpha_{1} \gamma}\left(\frac{a}{r}\right)^{4}\right] \cos (2 \theta)\right\} \\
\sigma_{r r}^{2} & =\sigma \alpha_{1} \gamma\left(\frac{1}{2 \alpha_{2}+\gamma-1}+\frac{2 \cos (2 \theta)}{1-\gamma+4 \alpha_{1} \gamma}\right) \\
\sigma_{\theta \theta}^{2} & =\sigma \alpha_{1} \gamma\left(\frac{1}{2 \alpha_{2}+\gamma-1}-\frac{2 \cos (2 \theta)}{1-\gamma+4 \alpha_{1} \gamma}\right)
\end{aligned}
$$
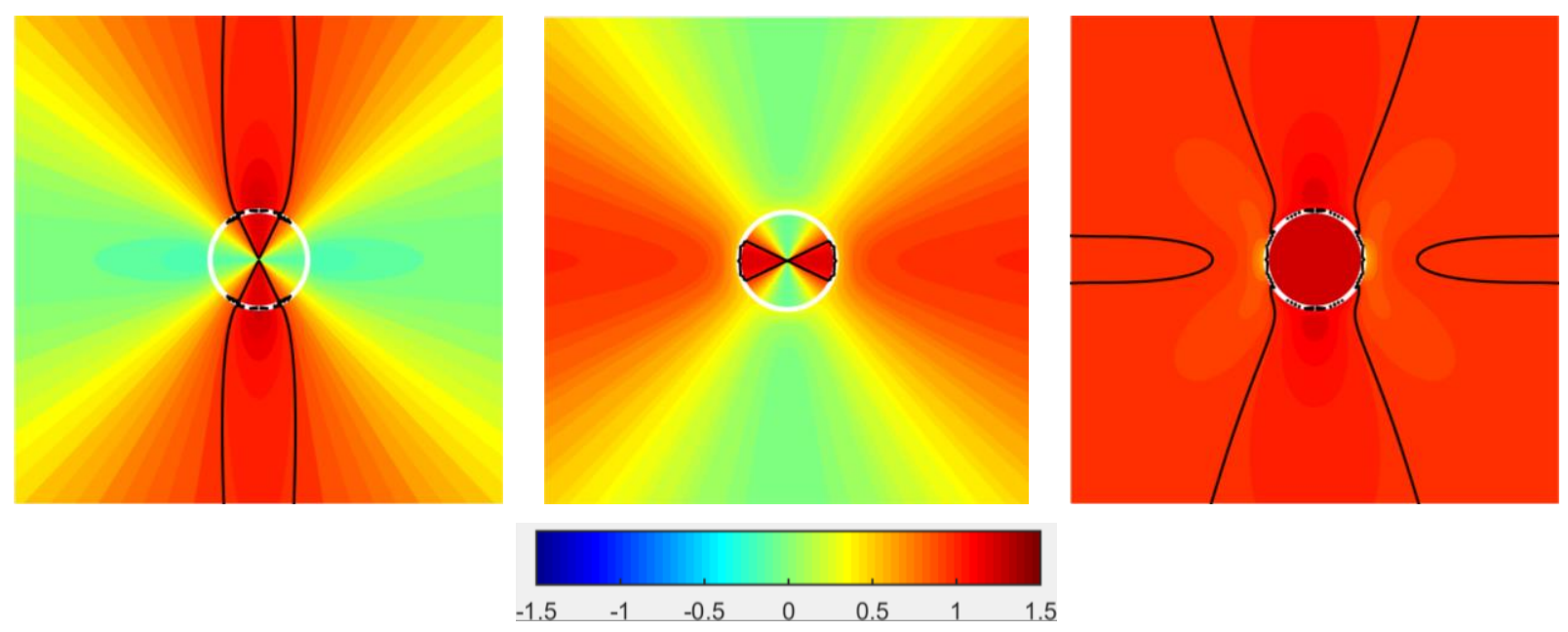

(a)

(b)

(c)

Figure 10. Distribution of stress concentrations around an idealized Si particle (white contour) in an aluminum matrix. Stress components are (a) radial, $\sigma_{\mathrm{rr}},(\mathrm{b})$ angular, $\sigma_{\theta \theta}$, and (c) von Mises. The black contour line indicates the stress concentration of 1 . The applied stress is along the direction of the page (vertical).

The simulation indicates that stresses are transferred from the matrix to the eutectic Si phase, thereby initially causing deceleration as the crack approaches the particle (due to a reduction in effective driving force), and subsequently acceleration as the crack debonds/fractures the particle. These results are in agreement with observations of a local change in the growth mode through the eutectic Si colonies within the intergranular space, depicted in Figure 
6 , as crack growth changes from crystallographic within the primary $\alpha$-Al dendrites to combined debonding/fracture of Si particles with mixed void coalescence and quasi-cleavage of the eutectic Al. It can thus be concluded that eutectic Si particles introduce a barrier effect to crack growth in early propagation stages, and this effect may be enhanced by processing means that increase the debonding/fracture resistance of the eutectic Si phase. Eutectic Si particle/interface strengthening would also positively affect later stages of crack growth when Si particles start acting as weak links ahead of the crack tip and facilitate propagation.

\section{DISCUSSION AND CONCLUSIONS}

Long and small FCG studies were conducted on A356-T6 cast Al alloys with various microstructural conditions in order to investigate their respective effects on the material's FCG resistance. Fractographic microscopy techniques and EBSD were used to determine crack growth mechanisms and identify controlling microstructural features at various crack growth stages. Based on the results of these investigations, the following conclusions are drawn:

- For long cracks, crack propagation mechanisms with respect to the microstructure are influenced by the crack driving force, $\Delta \mathrm{K}$. At low stress intensity, crack propagation is initially crystallographic cleavage of the $\alpha$ Al matrix, evolves to mixed-mode growth through the $\alpha$-Al matrix with occasional propagation around/through the eutectic Si particles at intermediate stress intensity, and finally predominantly follows the large eutectic Si colonies at high stress intensity. The change between these mechanisms is governed by the size of the plastic zone ahead of the crack and its ability to sample the distribution of Si particles. It was found that Sr-modification significantly improves the fracture toughness of the alloy, with minimal change in the threshold. Grain refinement was observed to decrease the threshold for long crack growth due to closure effects.

- The failure mode of the eutectic Si phase (debonding vs. fracture) changes with particle morphology and crack driving force. Sr-modified particles preferentially debond at low stress intensity $(\Delta \mathrm{K}<6 \mathrm{MPa} \sqrt{\mathrm{m}})$ and fracture at high stress intensity. The unmodified $\mathrm{Si}$ particle failure mode is determined primarily by the orientation of the particle with respect to the crack plane at low stress intensity, and occurs mostly by fracture at high stress intensity.

- MSC growth was investigated for Sr-modified A356-T6 in two grain sizes (500 and $1300 \mu \mathrm{m})$. Crack growth is crystallographic through the primary $\alpha$-Al matrix and mixed void growth/quasi-cleavage though the intergranular region. The fine-grained material has better FCG resistance in the MSC regime (in contrast with the long crack) due to increased number of microstructural barrier interactions, occurring at intergranular spaces consisting of eutectic $\mathrm{Si}$ and $\mathrm{Al}$ colonies.

- EBSD was used to investigate the fracture surface profile of the $500 \mu \mathrm{m}$ grain size specimen. The small crack had insufficient energy to change direction macroscopically and propagated through grains ahead of it independent of Schmid factors or twist/tilt angle. In the long crack regime, the crack has sufficient energy to avoid hard grains (low Schmid factor) and high twist angle boundaries.

- High-magnification EBSD and fractography confirm a local change in crack growth mode through the intergranular regions which contain "families" of spherodized eutectic Si crystals and fine-grained eutectic $\mathrm{Al}$ (from crystallographic through the primary $\alpha$-Al to void formation and ductile tearing within intergranular regions due to stress localizations). It is concluded from microstructural observations, EBSD data, and numerical models that the eutectic Si particles and grain boundaries enhance the MSC deceleration effect due to transfer of stress off of the matrix and blocked slip, respectively. However, the Si phase is also liable to ultimately debond/fracture due to stress redistributions, and becomes the point of failure, limiting the barrier effect and the high cycle fatigue response. For long cracks, high-magnification EBSD confirms the fractographic evidence of a local change in crack growth mode from primary $\alpha$-Al to increasingly weaker eutectic Si particles at the intergranular junctions. It also shows the presence of residual plastic stresses at $\mathrm{Si}$ colonies due to stress redistribution heterogeneity. 


\section{ACKNOWLEDGEMENTS}

This work was supported by the National Science Foundation (grant number 1151588) and the members of the Integrative Materials Design Center (iMdc) at Worcester Polytechnic Institute.

\section{REFERENCES}

[1] Lados DA, Apelian D, Donald J. Fatigue crack growth mechanisms at the microstructure scale in Al-Si-Mg cast alloys: Mechanisms in the near-threshold regime. Acta Materialia 2006;54:1475-86.

[2] Fleck NA, Smith IFC, Smith RA. Closure behavior of surface cracks. Fatigue of Engineering Materials and Structures 1983;6:225-239.

[3] Gan D, Weertman J. Crack closure and crack propagation rates in 7050 aluminum. Engineering fracture mechanics 1981;15:87-93.

[4] De Vadder D, Silk MG, Bouami D. Review of knowledge about diffraction of ultrasound by crack tip. Journal of Mechanical Behavior of Metals 1990;3:1-34.

[5] Pitoniak FJ, Grandt AF, Montulli LT, Packman PF. Fatigue crack retardation and closure in polymethylmethacrylate. Engineering Fracture Mechanics 1974;6:663-666.

[6] Irving PE, Robinson JL, Beevers CJ. A study of the effects of mechanical and environmental variables on fatigue crack closure. Engineering Fracture Mechanics 1975;7:619-630.

[7] Lee CS, Rhyim YM, Kwon D, Ono K. Acoustic emission measurement of fatigue crack closure. Scripta Metallurgica et Materialia 1995;32:701-706.

[8] Donald JK. Mechanics of Fatigue Crack Closure. Philadelphia, PA: American Society of Testing and Materials; 1988. p. 222-9.

[9] Lados DA, Apelian D, Paris P, Donald J. Closure mechanisms in Al-Si-Mg cast alloys and long-crack to smallcrack corrections. International Journal of Fatigue 2005;27:1463-72.

[10] Ritchie RO. Mechanisms of fatigue crack propagation in metals, ceramics and composites: Role of crack tip shielding. Materials Science and Engineering: A 1988;103:15-28.

[11] Zaiken E, Ritchie RO. On the Development of Crack Closure and the Threshold Condition for Short and Long Fatigue Cracks in 7150 Aluminum-Alloy. Metallurgical Transactions a-Physical Metallurgy and Materials Science 1985;16:1467-77.

[12] Wang QG, Apelian D, Lados DA. Fatigue behavior of A356-T6 aluminum cast alloys. Part I. Effect of casting defects. Journal of Light Metals 2001;1:73-84.

[13] Lados DA, Apelian D, Major JF. Fatigue crack growth mechanisms at the microstructure scale in Al-Si-Mg cast alloys: Mechanisms in regions II and III. Metallurgical and Materials Transactions A 2006;37:2405-18.

[14] Gavras AG, Chenelle BF, Lados DA. Effects of microstructure on the fatigue crack growth behavior of light metals and design considerations. Revista Matéria 2010;15:319-29.

[15] Buffière J-Y, Savelli S, Jouneau PH, Maire E, Fougères R. Experimental study of porosity and its relation to fatigue mechanisms of model Al-Si7-Mg0.3 cast Al alloys. Materials Science and Engineering: A 2001;316:11526.

[16] Zhai T, Jiang X, Li J, Garratt M, Bray G. The grain boundary geometry for optimum resistance to growth of short fatigue cracks in high strength Al-alloys. International Journal of Fatigue 2005;27:1202-9.

[17] Zhai T, Wilkinson AJ, Martin JW. A crystallographic mechanism for fatigue crack propagation through grain boundaries. Acta Materialia 2000;48:4917-27.

[18] Schaef W, Marx M, Vehoff H, Heckl A, Randelzhofer P. A 3-D view on the mechanisms of short fatigue cracks interacting with grain boundaries. Acta Materialia 2011;59:1849-61.

[19] Prasad Reddy GV, Robertson C, Déprés C, Fivel M. Effect of grain disorientation on early fatigue crack propagation in face-centred-cubic polycrystals: A three-dimensional dislocation dynamics investigation. Acta Materialia 2013;61:5300-10.

[20] Ludwig W, Buffière J-Y, Savelli S, Cloetens P. Study of the interaction of a short fatigue crack with grain boundaries in a cast $\mathrm{Al}$ alloy using X-ray microtomography. Acta Materialia 2003;51:585-98.

[21] Buffière J-Y, Ferrie E, Proudhon H, Ludwig W. Three-dimensional visualisation of fatigue cracks in metals using high resolution synchrotron X-ray micro-tomography. Materials Science and Technology 2006;22:1019-24. [22] Herbig M, King A, Reischig P, Proudhon H, Lauridsen EM, Marrow J, et al. 3-D growth of a short fatigue crack within a polycrystalline microstructure studied using combined diffraction and phase-contrast X-ray tomography. Acta Materialia 2011;59:590-601. 
[23] Spear AD, Li SF, Lind JF, Suter RM, Ingraffea AR. Three-dimensional characterization of microstructurally small fatigue-crack evolution using quantitative fractography combined with post-mortem X-ray tomography and high-energy X-ray diffraction microscopy. Acta Materialia 2014;76:413-24.

[24] Chen YQ, Pan SP, Zhou MZ, Yi DQ, Xu DZ, Xu YF. Effects of inclusions, grain boundaries and grain orientations on the fatigue crack initiation and propagation behavior of 2524-T3 Al alloy. Materials Science and Engineering: A 2013;580:150-8.

[25] Gall K, Yang N, Horstemeyer M, McDowell DL, Fan JH. The debonding and fracture of Si particles during the fatigue of a cast Al-Si alloy. Metallurgical and Materials Transactions a-Physical Metallurgy and Materials Science 1999;30:3079-88.

[26] Spangenberger AG. Engineering of Light Metals for Dynamic Properties and Fatigue Performance. Internal Report. Integrative Materials Design Center: Worcester Polytechnic Institute; 2015.

[27] Shankar S, Riddle YW, Makhlouf MM. Eutectic solidification of aluminum-silicon alloys. Metallurgical and Materials Transactions A 2004;35:3038-43.

[28] Makhlouf MM, Shankar S, Riddle YW. Mechanisms of formation and chemical modification of the morphology of the eutectic phases in hypoeutectic aluminum-silicon alloys. American Foundry Society2005. p. $145-62$.

[29] Major JF, Apelian D. A Microstructural Atlas of Common Commercial Al-Si-X Structural Castings. AFS International Conference on Structural Aluminum Casting. Orlando, FL, USA: American Foundry Society; 2003. [30] Mal AK, Singh SJ. Airy's Stress Function in Polar Coordinates. Serebreny C, editor. Deformation of Elastic Solids. Englewood Cliffs, NJ: Prentice Hall; 1991. p. 204-24. 